Culture et histoire dans l'espace roman

Écrire ailleurs : deux Moldavie(s)

\title{
À chacun sa Moldavie
}

\section{Marina Mureşanu Ionescu}

\section{OpenEdition}

\section{Journals}

Édition électronique

URL : https://journals.openedition.org/cher/10348

DOI : $10.4000 /$ cher.10348

ISSN : 2803-5992

\section{Éditeur}

Presses universitaires de Strasbourg

\section{Édition imprimée}

Date de publication : 1 décembre 2013

Pagination : 125-132

ISBN : 978-2-86820-560-5

ISSN : 1968-035X

\section{Référence électronique}

Marina Mureşanu Ionescu, «À chacun sa Moldavie », reCHERches [En ligne], 11 | 2013, mis en ligne le 08 février 2022, consulté le 09 février 2022. URL : http://journals.openedition.org/cher/10348 ; DOI : https://doi.org/10.4000/cher.10348

\section{cc) (i) (2)}

Ce(tte) œuvre est mise à disposition selon les termes de la Licence Creative Commons Attribution Pas d'Utilisation Commerciale - Partage dans les Mêmes Conditions 4.0 International. 


\title{
À chacun sa Moldavie
}

\author{
Marina Mureşanu Ionescu \\ Université «Alexandru loan Cuza » de laşi \\ Université Jean Monnet de Saint-Étienne
}

e titre de notre intervention est inspiré par le titre du roman d'une
(Chacun sa Budapeste), éditions Polirom, collection Ego Proza, Iaşi, 2007.

L'intervention se propose de réfléchir sur ou prolonger le questionnement qui nous a été proposé: est-il légitime de parler de deux ou plusieurs Moldavie(s) littéraires, artistiques, etc. La réponse est évidente par la force des choses: oui, il y a deux Moldavies, quelque bizarre que cela puisse paraître. Le problème épineux est comment fonctionne cette anomalie, cette "anormalité», comment se pensent et se conçoivent réciproquement ces deux versants d'une même entité.

Rappelons quelques bizarreries que les étrangers de partout ont un mal fou à comprendre: la même langue (à peu près), la même monnaie (le leu, lion), le même drapeau (à peu près), le même hymne national (pendant un certain temps), le même passé historique, avec les mêmes figures mythiques (Ştefan cel Mare, Alexandru cel Bun, etc.), les mêmes coutumes et traditions, la même religion (l'orthodoxie, avec la différence qu'elle est grecque en Roumanie, russe en Moldavie), la même littérature - étrangement, deux fois nationale - avec les mêmes repères (Eminescu, Creangă, etc.) et pourtant, deux pays qui ont, en plus, le même nom: la «Moldavie», du côté roumain, la «République de Moldavie» du côté... moldave, pour qu'il y ait quand même un petit élément de différence.

Nous nous proposons de présenter - en tant que pièces à verser à ce dossier compliqué - deux éléments découpés dans un espace qui est quand 
même, il faut l'admettre, le repère de ce que l'on pourrait nommer la moldavité. Il s'agit de la ville de Iași, capitale historique - indubitablement de la Moldavie, au sens large ou étroit et longtemps appelée «capitale culturelle de la Roumanie», plus récemment, "capitale de la francophonie sud-est européenne». Il y a sans doute une aspiration «capitaliste» de la ville de Iaşi.

Les deux exemples choisis pour notre discussion, trouvés d'ailleurs en liaison étroite, seront donc issus de la vie culturelle et littéraire de Iași: Timpul, Revue de culture et le le roman Fiecare cu Budapesta lui (Chacun sa Budapeste) de Gabriela Gavril.

L'auteure du roman est la rédactrice en chef de la revue depuis 2002. Gabriela Gavril est donc journaliste, romancière et universitaire en bonne et due forme, auteure d'une thèse de doctorat intitulée De la "Manifest» la "Adio Europa!». Cercul Literar de la Sibiu, Editions de l'Université "Alexandru Ioan Cuza» Iași, 2003. Pour cet ouvrage, Gabriela Gavril a reçu le Prix de début du Journal de Iași, en 2004. Comment ces dimensions coexistent-elles? On tâchera de le voir à travers la voix de l'auteure ellemême.

\section{Timpul, Revue de culture}

Quelle place la revue Timpul occupe-t-elle dans le paysage de la presse littéraire roumaine et de Iaşi, en particulier ?1

Iași a toujours été un centre de premier rang de la presse littéraire roumaine. Il suffit de rappeler que c'est ici que paraît en 1867, l'une des plus importantes et des plus glorieuses publications, la fameuse Convorbiri literare (Entretiens littéraires). La liste des parutions prouvant cette effervescence de Iași pour ce qui est de la presse littéraire serait longue. Dans les années 1960, fait son apparition une revue de culture hebdomadaire qui a joui d'un vif succès pendant plusieurs décennies, Cronica, en concurrence paisible avec Convorbiri literare dans une nouvelle forme. Que reste-t-il aujourd'hui de l'ancienne gloire? Convorbiri literare, Dacia literară, les vieilles dames, toujours aussi respectées, paraissent toujours et sont toujours de qualité, en bonne tradition provinciale. Mais leur lectorat est plutôt confidentiel. Cronica vivote, complètement tombée dans l'oubli d'autant plus qu'elle est

1 Voir aussi l'article consacré à la revue Timpul dans Dcționarul General al Literaturii Române, Academia Româna, coord. general E. Simion, Ed. Univers Enciclopedic, București, 2007, vol. S/T, «Timpul», I.I. [Ion Istrate], p. 714-715. 
devenue mensuelle. Soutenue vaguement par la mairie de Iași, elle a plutôt l'air d'un agonisant que l'on pourrait indéfiniment maintenir en vie grâce aux appareils. Les quelques tentatives post 1989, telle la revue Moldova (laquelle?) ont vite échoué, malgré un début prometteur et un beau projet initial.

Dans ce paysage essoufflé, la revue Timpul a mis du temps à s'imposer, à se faire connaître d'abord par un groupe restreint puis dans des cercles de plus en plus larges, diffusée aussi par voie électronique. Ce qui la différencie des autres publications de Iaşi c'est la diversité thématique qui en fait une vraie revue de culture, débordant le champ littéraire et touchant la réflexion philosophique, sociologique, historique ainsi qu'une problématique sociale et politique, traitée toujours avec modération. Timpul a une personnalité, un air de modernité qui dépasse largement la note provinciale si pesante à Iaşi. Timpul réunit des collaborations de partout en Roumanie et a des correspondants étrangers en France, Pays-Bas, Canada, USA, Grande Bretagne, etc.

Dans quelle mesure la revue Timpul est-elle ouverte aux écrivains et aux auteurs de l'autre Moldavie? Dans un premier temps, des poètes de Bessarabie, tels Leonida Lari et Grigore Vieru font partie du collège de rédaction renouvelé par la suite. Une rubrique Poètes de Bessarabie a existé pendant un certain temps. Les pages sont ouvertes mais non pas de façon préférentielle. Le critère qui semble primer c'est la qualité, quelle que soit la provenance géographique des auteurs. Pour donner un exemple plus récent, signalons dans le $\mathrm{n}^{\circ} 4$, avril 2011, une page consacrée à Mihail Vakulovski, écrivain moldo-roumain car il a obtenu le titre de docteur ès lettres à l'Université de Bucarest en 2002 et publie beaucoup en Roumanie. On publie, avec une présentation substantielle de l'auteur, un fragment de son «rockman», intitulé Student la Chişinău, le premier d'une trilogie annoncée, Tovarăşi de cameră, qui se propose de nous porter des deux côtés du Prut, dans, précise-t-on, "deux pays frères, deux mondes si rapprochés et en même temps si différents». Depuis, on retrouve dans Timpul, le nom de Mihail Vakulovski en tant que signataire d'une rubrique permanente de critique littéraire.

Timpul ne se propose donc pas de façon explicite d'être un "pont» (de papier) entre les deux Moldavies mais ne refuse pas de l'être si des textes de valeur lui parviennent. 


\section{Fiecare cu Budapesta lui de Gabriela Gavril}

C'est un roman surprenant, fort, qui frappe par une écriture sans concessions, dure, masculine, dirait-on, très loin du style universitaire standard.

A început să-mi pîlpîie o luminiță între sinapse şi l-am vizualizat pe Herr Direktor, cu fața lui de corcoduşă uitată pe plită, în patru labe, mişcîndu-şi posteriorul în temenele, proptindu-se din cînd în cînd cu nasul de adidaşii mei. Ajustez imaginea: îl pun să-şi ridice şi mîinile deasupra capului, ca musulmanii la rugăciune. Pe acritura care mă seacă la ficaţi de vreo cincisprezece ani am dotat-o cu trompetă de plastic şi-am cocoțat-o pe masa prezidiului. Arată în țoalele ei de bazar ca un gîndac-de-Colorado pleoştit de la piatra vînătă de primăvară. Promițător. ${ }^{2}$ (p. 18)

C'est un roman qui n'est pas passé inaperçu dans la production abondante d'après 1990, promue avec courage surtout par les éditions Polirom. Citons la chronique signée par Tudorel Urian dans România literară, n 31, 2007:

Chacun sa Budapest, de Gabriela Gavril est l'un des romans les plus savoureux écrits jusqu'à présent sur la transition roumaine [...]

Gabriela Gavril est une écrivaine mûre, pour qui l'écriture n'a plus de secrets depuis longtemps et son début en prose doit être salué. ${ }^{3}$

Le qualifiant de "postmoderne», Tudorel Urian compare le roman avec les films de Lucian Pintilie, Emir Kusturica ou Cristian Nemescu, pour son mélange tragi-comique, le grotesque et l'hyperréalisme.

L'idée de base génératrice du discours est celle d'un contraste, d'une déchirure entre un quotidien grotesque insupportable et un univers mental qui est "ailleurs» qui veut se protéger, se mettre à l'abri, se préserver désespérément:

Molfăi nişte onomatopei şi-mi dau seama, cu această ocazie, că se clatină lucrarea dentară pe care am dat o avere. Caut să mă duc undeva în Nirvana, scormonesc în minte după o mantră liniştitoare, oricum îmi repet în gînd «eu nu-s aici, astea nu se întîmplă, nimic din ce auzi tu nu se întîmplă». Încerc să-mi domolesc nervii amintindu-mi de mătuşa Rozalia, de tînguirile ei pe nas şi de salata de vinete amare, aşezată într-un catron avînd pe fund reproducerea Palatului Culturii, în romburi aurii. Care-i legătura? (p. 11)

2 L'article s'adresse à des lecteurs bilingues franco-roumains. Les citations sont données d'après l'édition citée, éd. Polirom, Iaşi, 2007. Les citations du roman ne seront pas traduites, étant d'ailleurs quasi intraduisibles, vu que le style de l'auteure est fortement imprégné d'une oralité roumaine contemporaine qui serait anéantie par la traduction. Dans toutes les citations, nous avons maintenu l'orthographe utilisée en 2007.

3 C'est nous qui traduisons. 
Deux plans - présent / passé - s'articulent selon un mécanisme proustien et cette question: "Care e legătura? » (Quel est le rapport?) semble être une clé. Non, il n'y a pas de lien apparent et logique entre les fragments d'une réalité où le grotesque, le comique et le tragique se côtoient, se juxtaposent. Gabriela Gavril reconnaît l'influence d'auteurs est-européens moins connus en Roumanie, des Polonais en particulier, qu'elle a pu lire dans l'original, comprendre autrement, lors de ses séjours prolongés à Cracovie en tant qu'enseignante de roumain à l'Université Jagellonia: Konwicki, Mrozek, Bruno Schulz, Czeslaw Milosz, Adam Zagajewski ou le Hongrois Sandor Marai.

Comment s'articulent chez Gabriela Gavril l'universitaire, l'écrivain et le journaliste? Elle nous l'explique dans une interview accordée en octobre 2011:

Je ne me suis jamais imaginé que je serais une "universitaire», ce fut un peu un hasard. Je n'ai jamais pu vraiment accepter - même jusqu’à présent - les contraintes de la bureaucratie universitaire, je suis effrayée par la "ghettoïsation» des universités et je me répète les dires de Peter Sloterdijk, l'auteur de la Critique de la raison cynique: on devrait inventer une autre maturité, puisque celle d'à présent est lamentable, vouée à l'échec. Si durant toutes ces années je n'avais pas écrit de la prose (plus ou moins réussie, beaucoup d'essais, des «arpèges») je ne sais pas si j’aurais résisté comme universitaire. Lorsqu'on regarde le monde en prosateur, les choses deviennent un peu plus supportables. Tout ce qui se passe autour commence à intéresser (même les situations les plus ineptes), le passage des personnes aux personnages acquiert une fonction exorcisante. Mais je ne souhaiterais pas écrire de la prose sur le milieu universitaire, comme le fait David Lodge, si savoureux (et tristes au fond) que soient ses livres. Ce serait trop peu [...]

Mes textes de journaliste sont issus de mon effort de comprendre certains changements de mentalité, certaines zones du quotidien, les modalités de manipulation des masses, la pathologie des discours public, etc. À partir des mêmes données, j’ai parfois écrit en parallèle des proses courtes, études et articles de journal. Je ne sais pas si mes textes ont jamais pu servir aux autres, pour moi ils ont toujours été et le seront un exercice d'analyse et d'auto-analyse. ${ }^{4}$

Chacun sa Budapest est en fait un roman de la solitude: chacun son monde, chacun sa perspective, chacun sa direction où que ce soit dans le monde, pourvu que l'on échappe à une Roumanie dévastée, éclatée dans une «transition» sans fin:

4 C'est nous qui traduisons. 
- Fiecare cu Budapesta lui... Mai dă-mi vin.

S-a ridicat dintr-o dată :

- Uită-te în jur, uită-te..., tu nu vrei nimic de pe aici? Am casa plină de zdrențe, de vechituri lăsate de alții, cînd s-au dus, s-au dus, s-au dus, unde-i soare şi bine. «Eu plec în Canada... na-ți frigiderul, mai sînt şi nişte pahare şi-o zaharniță...», "M-am angajat în Germania, deocamdată temporar, ca asistent laborant, ăştia au o secție de spectometrie... şi nu mai vin înapoi... am o casetuță pentru bijuterii şi căciula asta de blană, ți-ar veni, poți s-o mai transformi, am şi-un sacou pentru tine... a, pot să aduc la tine nişte ferigi? » «Eu rămăn în Franța, ia-l pe Călinescu, n-am ce să fac cu el... şi covoraşul ăsta, poate-ți trebuie, ce număr porți la pantofi? «Mi s-au aprobat actele pentru Noua Zeelandă... uite-aici televizorul, e încă în garanție, un dulăpior, ăi pui tu mînerele, sînt în pungă, o etajeră, cîteva discuri... » A, pînă şi Alexandru, cînd s-a cărat în State, mi-a adus o hotă cu tot cu filtre... (p. 151)

Une séquence d'errance dans la ville de Budapest, vers la fin du roman, a une fonction de mise en abyme et serait une explicitation du titre:

De undeva, pe strada îngustă, se-aude înfundat o sirenă. Parcă iese din ziduri, nu trece nici o mașină. Lumea doarme încă, ferestrele sînt acoperite de obloane ghintuite, nu se zăresc trecători. Ştiu că femeia ămi arătase, din cap, direcția asta. Dacă totuşi nu e cea bună? Nu ajung nicăieri, aceleaşi ziduri, porțile îchise, aş fi vrut să ies în centrul Budapestei sau undeva pe malul Dunării, lîngă podul acela mare, străjuit de statui, poate în insula Margareta. Mi-aud paşii, sună ciudat pe caldarîm, o clădire înaltă, de o austeritate romană, de-acum n-am încotro, am să merg mai departe, trebuie să ducă undeva. După un colț, piața de peşte. Merg agale, deasupra soarele se-mperechează cu zidul, rămîn împreună, uniți ca două verigi. (p. 268-269)

Comme de nombreux romans roumains actuels de la jeune génération (ou moins jeune), le roman de Gabriela Gavril est fortement imprégné de souvenirs de l'enfance et l'adolescence vécues sous le communisme, en contrepoint avec les mutations de la transition postcommuniste:

Tramvaiul mă lasă la rond. Fabrica de mătase nu mai are geamuri, în trotuarul spart au crescut tufe pănă la genunchi. Nişte țevi imense şi profilurile din beton lîngă poartă. Altădată, mai ales la ieşirea din schimb, era un furnicar de oameni pe stradă, plecau pe jos, în coloană, ca la demonstrație, sau agățați de uşile tramvaielor, mulțumiți c-au mai scos vreun cupon ascuns în cracii pantalonilor sau sub fuste, nişte eşarfeşi sutiene bunede schimbat pe Vegeta, conserve ruseşti sau fiare de călcat şi vreo sticluță de colorant după care se dau în vînt ăia din mahalaua de la Palat. Acum e o linişte suspectă. Cei mai mulți au luat drumul Irlandei sau al Spaniei, cei mai bătrîni s-au întors la țară, pe lîngă vreo bucată de pămînt. Înainte erau buni, ei prindeau cozile, 
stăteau cu scăunelele zile întregi, veneau cu sacoşele cu hîrtie igienică, țineau casa, acum nu mai are nimeni nevoie de ei. (p. 95-96)

Mais Chacun sa Budapest est d'abord le roman de Iaşi. Il est écrit par un habitant de Iaşi pour les habitants de Iaşi. Les différents endroits - Copou, Palat, Piața Unirii, Bilbioteca, Statuia lui Eminescu, Podu Roș, Mitropolia, telle ou telle adresse - sont insérés dans la pâte romanesque comme si tout le monde les connaissait. Parfois Iași est vue comme une ville qui «se meurt», bien que la vie littéraire, la presse, l'université soient présentes, la plupart du temps sur le mode grotesque.

Ei, unii se plîng la noi că moare oraşu', că suntem coada României, că, vorba ceea, de-aici ori fugi la gară, ori o iei spre cimitir, că nu mișcă nimic, dar io zic că-n vreo doi ani, cel mult, se pune pe picioare. Așa-i? (p. 51)

E absolut imposibil să găsești în orașul ăsta un loc normal în care să bei o cafea. Ai cantine staliniste, hale reci, dughene chinezești, bombe nenorocite duhnind a mahoarcă și așa-zise cafenele mai spălate, un fel de fast-fooduri cu gresie, metal și mese de plastic. Toate cu muzica dată la maximum. (p. 206-207)

Et la conclusion: c'est une ville où il est même impossible de se suicider. Et pourtant:

$\mathrm{Ce}$ ? Aici e oraşul meu, aici m-am născut, aici aş vrea să mor... (p. 96)

Et la Moldavie - l'une et l'autre - où est-elle? Iași est la plus grande ville moldave mais les "scènes», les «fragments", les "clichés» surpris pourraient se situer n'importe où. On ne peut pas identifier quelque chose de spécifiquement «moldave» (côté roumain). Il y a, par contre, des pages mémorables sur les Moldaves d'au-delà du Prut, sur la façon dont ils sont vus, perçus, subis par les habitants de Iași, donc de Roumanie, donc de l'Europe. Le clivage, la faille ne semble pas facile à dépasser: pour l'instant, chacun sa Moldavie, chacun sa Budapeste, selon la direction que l'on emprunte.

Et, pour finir, un portrait du Moldave moldave brossé par un(e) Moldave roumain(e) et de Iaşi, n'oubliant pas que les habitants de Iaşi sont ceux qui les voient, les perçoivent le plus, le mieux et du plus près:

- Îmi pare rău de amărîții ăia din Basarabia, da’ de noi plîng de se scutură cămaşa, poate-o să ne unim pînă la urmă... Îi vezi cum trec prin vamă cu traiste de pătrunjel, rațe, gîște, să le vîndă dincoace, să mai facă un ban. Ştii, mi-a zis mie unul că-şi dresează orătăniile, le dau drumul să vină-n zbor sau pe apă pîn-aici. Ştii care-a fost cea mai tare fază cu podurile cu frații ?

- ...au fost mai multe... 
- Ei, nu, asta le lasă binişor în urmă pe toate. Acum două duminici, vînzoleală mare, mascați, pompieri, au aruncat hodrobelele cimotiilor să poată intra, să tragă furtunul cu apă... Ce crezi că era?

- ?! ?, ridic din umeri.

- Un rusnac care scosese frumuşel la vînzare, pe tarabă, lîngă țăranii cu varză, barabule, fasole... două kalaşnikoave, grenade, cartuşe, încărcătoare... Le aliniase omu' şi-aştepta cumpărător.

- Hai că...

- Aştepta el, l-au pus la pămînt mascații şi rusnacu' supărat de acolo : «Uăi băiețî, da' io cridem cî la voi îi dimocrațîi de-amu...»

- Ce-o fi înțeles el prin «dimocrațîi»? (p. 48-49)

Doit-on conclure? Doit-on placer Gabriela Gavril et son roman dans une case? Doit-on généraliser et dire : voilà ce que sont les deux Moldavies? Sûrement pas. Laissons les portes et les "ponts» ouverts... Comptons sur le temps et peut-etre - pour boucler la boucle - sur Timpul, dont il a été question plus haut. Et sur Gabriela Gavril, romancière, journaliste, professeur, comme tant d'autres de cette génération postmoderne d'un pays qui se cherche. 